\title{
Save the planet or close your eyes? Testing strategic ignorance in a charity context*
}

\author{
Jo Thori Lind, Karine Nyborg, Anna Pauls ${ }^{\dagger}$
}

Monday $11^{\text {th }}$ February, 2019

\begin{abstract}
Do people try to avoid unpleasant information about the environmental consequences of their actions? If so, do they react with hostility towards others who provide the unwanted information? Fearing such hostility, do others abstain from providing the information? These are the questions we set out to explore by means of lab experiments presented here. To our surprise, and in stark contrast to related previous literature, we found few indications of willful ignorance. In a binary dictator game with an environmental charity as the recipient, an option to stay uninformed about the effects of one's actions for the charity was infrequently chosen, and did not significantly affect generosity. When another subject might choose to impose information on the dictator, almost all dictators asked for information themselves - but this was not associated with increased dictator generosity. We argue that the phenomenon of strategic ignorance is likely to be less robust and more contextdependent than one might expect based on previous research, and that this result may be important from an environmental policy perspective.
\end{abstract}

Keywords: Strategic ignorance, dictator game, experiment, social sanctions, carbon offset JEL classification: C92, D63, Q50

*We are grateful for funding provided by the Oslo Centre for Research on Environmentally Friendly Energy (CREE) and the Centre for the study of equality, social organization, and performance (ESOP). Thanks to participants at a number of workshops, seminars, and conferences as well as friends and colleagues for their helpful comments. We are also grateful to anonymous pilot participants, to Zack Grossman, Karen Hauge and Joël van der Weele for sharing their code, to You Wu for competent research assistance and Kjell Arne Brekke and Elisabeth T. Isaksen for fruitful cooperation on the recruitment of participants.

${ }^{\dagger}$ Department of Economics, University of Oslo, Norway 


\section{Introduction}

If someone tells you that your current behavior is damaging the environment, you would probably feel a bit uncomfortable. But does the prospect of such a situation make you behave in a more environment-friendly way? Or do you rather shy away from situations likely to confront you with unpleasant information?

Previous laboratory experiments have demonstrated the prevalence of strategic ignorance: ${ }^{1}$ when given the option to remain ignorant about the consequences of one's actions for someone else, a substantial share of subjects choose ignorance - resulting in a substantial reduction in overall generosity compared to when subjects cannot avoid information. It may seem, thus, that while people feel responsible for preventing known negative effects on others, they feel less responsible for finding out whether negative consequences are present.

Casual observation indicates that strategic ignorance could play a role for environmental problems as well. Lack of knowledge concerning such issues seems quite common - climate change skepticism, for example, is surprisingly widespread. If this is due to information acquisition being costly, this would have a straightforward solution if others could easily transmit the missing information to those still unaware of it. If the recipient does not welcome the information and prefer to avoid acquiring information, however, matters become more complicated. The problem is not limited to the recipient's possible lack of attention: bearers of unwanted information may face frowns, ridicule, or outright hostility, making them hesitate to convey information in the first place. If friends invite you for dinner and they serve steaks, you may not feel tempted to use that opportunity to tell them about the climate impacts of red meat production. If a colleague tells you she is flying to Greece for vacation, informing her about the exact amount of carbon emissions caused by her travels might not make you more popular.

These observations gave rise to the research questions we set out to explore in the present study. If lack of information allows one to escape a feeling of social and/or moral responsibility for environmental problems, people may prefer to avoid information about such problems. If so, avoiding information could produce less environment-friendly behaviors. An on-looker conveying the avoided information may be faced with social sanctions; foreseeing this, the on-looker may abstain from conveying the information in the first place.

In the lab experiment presented below, we explored this by means of a binary dictator game inspired by Dana, Weber, and Kuang (2007). Since our study was motivated by the question of how people relate to environmental information, the recipient in our study was not another lab participant, as in Dana, Weber, and Kuang (2007) and replications, but a charity engaged in climate projects in poor countries. Two of our treatments were very similar to the design applied in Dana, Weber, and Kuang (2007), which we return to below. Our primary interest, however,

\footnotetext{
${ }^{1}$ The seminar paper is Dana, Weber, and Kuang (2007), followed up by e.g. Larson and Capra (2009); Matthey and Regner (2011); Feiler (2014); Grossman (2014); van der Weele, Kulisa, Kosfeld, and Friebel (2014); Regner and Matthey (2015); Exley (2016); Hertwig and Engel (2016); Spiekermann and Weiss (2016); Grossman and van der Weele (2017); d'Adda, Gao, Golman, and Tavoni (2018); Felgendreher (2018)
} 
lies in three additional treatments involving a third party, a messenger. The purpose of this was to study whether a person providing unwanted information on environmental consequences - a messenger - would face sanctions from the recipient of that information - and if so, whether such potential sanctions would discourage messengers from providing information in the first place. To our knowledge, ours is the first study to explore the role of social interaction in a strategic ignorance context.

To our surprise, however, our findings on the prevalence of strategic ignorance turned out to be very different from those reported in Dana, Weber, and Kuang (2007) and replications - also without messengers. Although our material incentive structure was identical to the one used by Dana, Weber, and Kuang (2007), a much lower share of dictators in our experiment $-5 \%$ to $22 \%$, depending on the treatment - chose to remain ignorant about the consequences of their actions. More importantly, and in contrast to Dana, Weber, and Kuang (2007) and replications, the option to remain ignorant did not significantly increase selfish behavior. Thus, although some dictators chose ignorance, this could simply reflect lack of interest in the information rather than strategic ignorance.

In retrospect, our experimental design was not optimal; it was not designed to control for possible explanations for this surprising lack of strategic ignorance, and given these results, the messenger treatments were less informative than expected. Nevertheless, our results made us suspect that, although strategic ignorance has been observed repeatedly in the literature, this phenomenon may be quite sensitive to contextual changes.

Most experiments on strategic ignorance, including ours, involve binary versions of the dictator game. There is, by now, a huge literature on dictator games (e.g. List 2007, Cappelen, Nielsen, Sørensen, Tungodden, and Tyran 2013, Lazear, Malmendier, and Weber 2012, Cherry and Shogren 2008; for an overview see Engel 2011). One interpretation of this literature is that dictator generosity is determined by subjects' perceived moral and/or social obligations, which are, in turn, highly context-dependent.

In dictator games involving strategic ignorance, the feeling of moral and/or social obligation is presumably exactly what subjects are trying to escape by avoiding information. If the felt obligation to contribute is highly context-dependent, then so are, presumably, behaviors motivated by the avoidance of such obligations. Viewed from this perspective, it seems reasonable to expect strategic ignorance to be strongly context-dependent.

If strategic ignorance is indeed a rather fragile phenomenon, understanding when it should and should not be expected to appear may be crucial to achieve efficient transmission of environmental knowledge to the public, and to foresee behavioral responses to various forms of environmental information campaigns. While our experiment cannot provide final answers to exactly why we did not replicate previous strategic ignorance results, it provides a starting point for the further experimental research needed to clarify this question.

Below, we first discuss the related literature, before presenting our design and discussing the results in more detail. 


\section{Literature and background}

As already discussed briefly above, recent literature has demonstrated that generosity is highly context dependent (List, 2007; Cox, List, Price, Sadiraj, and Samek, 2016). While most people do share with others when placed in a 'sharing context' like standard versions of the dictator game (Camerer, 2003), their sharing does not appear to be (exclusively) motivated by a concern for the other's payoff or well-being as such. For example, if given the opportunity to escape from the dictator role, even at a cost, a large share of dictators choose to do so, leading to less favorable outcomes for the recipient (Dana, Cain, and Dawes, 2006; Broberg, Ellingsen, and Johannesson, 2007; Jacobsen, Eika, Helland, Lind, and Nyborg, 2011; Lazear, Malmendier, and Weber, 2012; DellaVigna, List, and Malmendier, 2012). Varying the dictator game in other ways that blur the dictator's responsibility - such as making the selfish option an automatic default if the dictator waits unusually long before making her choice - also tends to produce more selfish choices (Dana, Weber, and Kuang, 2007). It may seem that individual feelings of moral responsibility are context-dependent (Cox, List, Price, Sadiraj, and Samek, 2016), and moreover, that responsibility is a burden individuals are reluctant to accept (Brekke, Kipperberg, and Nyborg, 2010; Nyborg, 2011). Thus, although a person may share generously in a context making her feel obliged to do so, she may prefer to avoid such contexts altogether.

Along similar lines, Dana, Weber, and Kuang (2007) showed that the option to stay ignorant about the consequences of one's decision induces more selfish behavior. Their study was followed by a surge of empirical as well as theoretical research on willful ignorance (Larson and Capra, 2009; Matthey and Regner, 2011; Feiler, 2014; Grossman, 2014; van der Weele, Kulisa, Kosfeld, and Friebel, 2014; Regner and Matthey, 2015; Exley, 2016; Hertwig and Engel, 2016; Spiekermann and Weiss, 2016; Grossman and van der Weele, 2017; d'Adda, Gao, Golman, and Tavoni, 2018; Felgendreher, 2018).

The basic version of the Dana, Weber, and Kuang (2007) lab experiment faces subjects with a binary dictator situation. The recipient is another participant in the same room, matched anonymously and randomly with the dictator. In their Baseline treatment, being kind to the recipient implies forgoing a part of one's own payoff, with the benefits to the recipient being larger than the cost for the dictator. If the dictator chooses X, she gets 6 USD and another subject gets 1 USD. If she chooses $\mathrm{Y}$, she and the other subject both get 5 USD. ${ }^{2}$ Note that $\mathrm{Y}$ is not only the pro-social but also the more efficient choice. This yields the payoff matrix shown as Panel A of Table 1.

In Dana et al.'s (2007) Hidden Payoff treatment, the dictator does not know from the outset which out of two possible sets of payoffs to the recipient applies. With probability $1 / 2$, the recipient's payoffs are as in Panel A of Table 1, otherwise the payoffs to the recipient is switched between alternatives, corresponding to the payoff structure shown as Panel B of Table 1. Notice

\footnotetext{
${ }^{2}$ Dana, Weber, and Kuang (2007) use the notation A and B for the two choices. In our social interaction part, we used A and B to refer to the two types of subjects. We therefore use our notation for the two choices here.
} 
Table 1: Payoff structures in Dana, Weber, and Kuang (2007)

A. Conflicting payoffs

\begin{tabular}{|c|c|c|}
\hline Dictator chooses & Dictator gets & Recipient gets \\
\hline $\mathrm{X}$ & 6 & 1 \\
\hline $\mathrm{Y}$ & 5 & 5 \\
\hline
\end{tabular}

B. Aligned payoffs

\begin{tabular}{|c|c|c|}
\hline Dictator chooses & Dictator gets & Recipient gets \\
\hline $\mathrm{X}$ & 6 & 5 \\
\hline $\mathrm{Y}$ & 5 & 1 \\
\hline
\end{tabular}

Notes: In the Baseline treatment, all subjects get Payoff matrix A. In the Hidden Payoff treatment, they know that both payoff structures are possible but they do not know which they face.

that the dictator knows his own payoff; the uncertainty is only about the payoff for the recipient.

That is, the dictator does not initially know whether she is in a situation of conflicting interests between the recipient and herself, or in a situation where their interests are aligned. However, the dictator can costlessly press a button to reveal which state applies for her, and thus make an informed choice. If she does not press the button, she makes her decision without knowing the payoffs to the recipient.

In the baseline treatment of Dana, Weber, and Kuang (2007), only 26\% choose the selfish option X. In the Hidden Payoff treatment, this number increases to 63\%, counting only subjects who actually are in the conflict state (whether they know it or not). ${ }^{3} 56 \%$ of all subjects (50\% of those in the conflict state) remain ignorant. $86 \%$ of ignorant subjects (100\% counting only those in the conflict state) choose X. Thus, the option to remain ignorant about the receiver's payoff increases the prevalence of selfish choices.

Later studies largely confirm these findings. Larson and Capra (2009) repeat Dana et al.'s (2007) experiment in a double-blind version without computers, but force participants to make an active choice between knowing or not knowing the consequences of their actions for the recipient. They find roughly similar results as Dana, Weber, and Kuang (2007): in the baseline treatment with payoffs corresponding to the Baseline payoffs above, only $22 \%$ choose the selfish option X. In their Hidden Payoff treatment, where subjects did not know which of the two matrices applied and had to make an active choice whether to be informed or not, $53 \%$ of dictators chose to stay ignorant; moreover, as much as $63 \%$ of the dictators (when in a conflicting state) chose $\mathrm{X}$ - and all the subjects who chose to stay ignorant did so.

Grossman (2014) also qualitatively replicates the findings of Dana, Weber, and Kuang (2007). However, when he makes the choice to stay ignorant an active choice, ignorance rates drop from $45 \%$ to $25 \%$. This indicates that exploitation of moral wiggle rooms is context sensitive. Grossman and van der Weele (2017) show that subjects are even willing to pay to remain

\footnotetext{
${ }^{3}$ If all subjects are included, both those in the conflicting and aligned interest states, $72 \%$ choose $\mathrm{X}$.
} 
ignorant, and that those who do so, make choices that are more selfish. Their results also indicate that curiosity can be a reason to reveal information, even for a person whose choice is unaffected by the receiver's payoff: in their study, ignorance is much lower when the receiver's payoff can be revealed only after having chosen between X and Y. Matthey and Regner (2011) use a dictator game with a rather different design, but still find that an option to stay ignorant about consequences of one's choices for another participant decreases generosity.

We are aware of only one previous lab experiment that explores strategic ignorance with a charity as the recipient. Exley (2016) reports results from a strategic ignorance game with a charity recipient. She used this experiment mainly to classify subjects in a study of risk (not ignorance) as an excuse for not giving, so the results are reported only in her Appendix C. Exley finds that the option to stay ignorant leads to substantially more selfish choices. In particular, $55 \%$ of her subjects choose to remain ignorant, and of these, $98 \%$ opt for the selfish option (across aligned and non-aligned states). ${ }^{4}$

A few studies observe strategic ignorance, but also find that certain design features affect its prevalence. Grossman (2014) replicates the main results from the Baseline and Hidden Payoff treatments in Dana, Weber, and Kuang (2007)'s study, but add treatments that vary the extent to which staying ignorant is an active choice. In contrast to Larson and Capra (2009), he finds that results depend on the ignorance option being a passive choice: when no information is the default, $45 \%$ of dictators stay ignorant; if the dictator is forced to make an active choice, this drops to $25 \%$, and if being informed is the default, only $3 \%$ of dictators stay uninformed. Van der Weele (2014) further finds that a decrease in the personal cost of implementing a fair allocation lowers the incidence of willful ignorance and increases pro-sociality. He does not find, however, that increasing the potential losses or gains of recipients affects ignorance or pro-social behavior substantially.

Also based on the design of Dana, Weber, and Kuang (2007), Feiler (2014) replicates the result that an option to stay ignorant increases selfish behavior. By varying the probability that the conflicting versus aligned interest state applies, she finds that ignorance is more prevalent when the probability of the aligned state is higher.

Two recent studies, both of them based on different designs than Dana, Weber, and Kuang (2007), observe very low levels of strategic ignorance. Thunström, Cherry, McEvoy, and Shogren (2016) explore whether dictators actively seek or avoid information concerning the deservingness of their recipient. They find that four out of five dictators choose to seek information and adapt their generosity accordingly, being more generous towards the 'deserving'. Felgendreher (2018) studies how consumers access information about ethical certificates, and

\footnotetext{
${ }^{4}$ From the dictator game literature, it is well known that a "deserving" recipient tends to increase generosity in dictator games (e.g. Eckel and Grossman, 1996; Fong, 2007; Cappelen, Halvorsen, Sørensen, and Tungodden, 2017). It is not a priori obvious how this would affect the prevalence of strategic ignorance. On the one hand, a more deserving recipient may increase dictators' wish to share; on the other, the very fact that she will feel more strongly obliged to share if discovering that the conflict state applies, could increase her temptation to stay ignorant.
} 
whether this influences purchasing decisions in an experimental market. He finds that consumers do not systematically ignore information, at least as long as information is costless. However, this result turns out to be surprisingly price sensitive: once a small cost of information is introduced, most consumers do not acquire information, and the share of consumers buying the certified product decreases significantly.

To sum up, a substantial number of studies have replicated the finding that an option to stay ignorant produces willful ignorance and comparatively low levels of generosity. Building on this literature, our study takes one step further to explore, in an environmental context, whether others will provide the willfully avoided information. Our main finding, however, is that even with an incentive structure identical to Dana, Weber, and Kuang (2007), the information does not appear to be unwelcome in our context. ${ }^{5}$

\section{Experimental design and procedures}

Like several of the studies cited above, the basic versions of our experimental design without messengers are based on the Baseline and Hidden Payoff treatments of Dana, Weber, and Kuang (2007). However, instead of another experimental subject, the recipient is a charity promoting climate projects in poor countries. To our knowledge, this is the first study to explore strategic ignorance in a global warming context.

The recipient is the organization Myclimate. Subjects are given the following information about the organization:

In the course of the experiment, money will also be donated to climate change projects in poor countries through the organization Myclimate. All climate projects supported by Myclimate are either recognized by the UN (so-called CDM quotas) or calculated and controlled according to the UN scheme (CDM scheme). The climate projects follow the so-called Gold Standard, which among other things involves a focus on sustainable development where the measures are implemented.

We use a between-subjects design. The relative payoffs are the same as in Dana, Weber, and Kuang (2007), but numbers are converted into Norwegian kroner (NOK) and adjusted for the different price level in Norway. ${ }^{6}$

In our Baseline treatment, all subjects face the same binary dictator situation. They were provided with a table corresponding to Panel A of Table 2.

They were also told that if the dictator chooses X, she gets 120 NOK and Myclimate gets 20 NOK. If she chooses Y, she and Myclimate both get 100 NOK.

\footnotetext{
${ }^{5}$ This does not, however, affect the prevalence of selfish choices. Rather, it seems that those subjects who only care about their own payoff do not bother to reveal information.

${ }^{6}$ At the time of the experiment, 1 NOK was worth 0.117 EUR.
} 
Table 2: Payoff structures

A.

\begin{tabular}{|c|c|c|}
\hline & You get & Climate projects get \\
\hline You choose X & 120 & 20 \\
\hline You choose Y & 100 & 100 \\
\hline
\end{tabular}

B.

\begin{tabular}{|c|c|c|}
\hline & You get & Climate projects get \\
\hline You choose X & 120 & 100 \\
\hline You choose Y & 100 & 20 \\
\hline
\end{tabular}

Notes: In the Baseline treatment, all subjects get Payoff matrix A. In all other treatments, they know that both payoff structures are possible but they do not know which they face.

In our Hidden Payoff treatment too, all subjects face a binary dictator situation, but here they do not initially know whether their own and Myclimate's interests conflict or align. Subjects are provided with two tables, one identical to Panel A and one identical to Panel B of Table 2.

Subjects are told that the payoffs are either as in Panel A or as in Panel B of Table 2, that the relevant table varies between participants, and that they do not know which table applies for themselves. The participants are not, however, told the probabilities for each state. The true probability of the conflict state was, in fact, 0.9 , because observations from the aligned state would give considerably less useful data for our messenger treatments. ${ }^{7}$

By clicking on a button marked "Show correct table" at the bottom of the screen, subjects could costlessly get to know which table was the correct one for them. Alternatively, they could ignore this button and instead choose "Continue", leading directly to the next screen in which they would then decide between $\mathrm{X}$ and $\mathrm{Y}$ without knowing the payoffs to Myclimate.

In addition to the Baseline and Hidden Payoff treatments, we ran three treatments designed to explore social interaction: Hypothetical Messenger, Stranger and Partner. In each of these treatments, half of the subjects were randomly assigned the dictator role (referred to as "A types" or "A persons"). Participants were presented with two tables, corresponding to the Hidden Payoff treatment above. They were informed that Dictators (A types) were to choose between $\mathrm{X}$ and $\mathrm{Y}$; that one of the tables applied for each A person with different tables for each $\mathrm{A}$ persons; and that each person did not know her own table, as described in Section 3.

The other half of the subjects were assigned the role of a messenger (referred to as "type B" or "B person"). Each dictator was paired anonymously with a randomly assigned messenger. The messenger's task was to answer "yes" or "no" to the following question:

\footnotetext{
${ }^{7}$ This implies that subjects were faced with ambiguity, not just uncertainty as in Dana, Weber and Kuang (2007), which may possibly have affected behavior. Moreover, while we find it unlikely that subjects suspected the high probability of the conflict state, we cannot exclude this possibility, since we unfortunately did not elicit beliefs about this in the post-experimental questionnaire. Alternatively, we could have used the strategy method; however, this method also has drawbacks in the current context, for example by possibly making subjects aware of otherwise (semi-)unconscious reasoning.
} 
Assume that a type A person is going to choose between $\mathrm{X}$ and $\mathrm{Y}$, but has chosen not to check which table is the correct one for him/her. If you had the possibility, would you wish to inform the A person about this?

Type B was assigned 100 NOK for her participation independent of her answer. After having chosen between $\mathrm{X}$ and $\mathrm{Y}$, however, type A was free to take up to $50 \mathrm{NOK}$ of a messenger's endowment. The latter was introduced to test whether messengers providing unwanted information would be faced with sanctions from the recipient of the information, i.e. the dictator they were paired with.

The three messenger treatments varied with respect to whether the type B person's answer about providing information was hypothetical or implemented. Further, we varied whether the messenger a dictator can take from was randomly chosen, or was the same person who could impose information on the dictator.

All subjects were informed about all rules before the experiment starts, and before types are drawn. Messengers learned neither which table/ state applied to the dictator matched with her, whether the dictator had chosen to acquire information, nor whether dictators chose $\mathrm{X}$ or $\mathrm{Y}$.

Hypothetical Messenger treatment. All subjects are informed that the messenger's answer will not affect any A subject - the question is purely hypothetical. Moreover, the dictator may take up to 50 NOK from a randomly drawn messenger's endowment. Participants are informed:

If you are type A, you will have the possibility to take up to $50 \mathrm{NOK}$ from a participant of type B. If you use this possibility, the amount you take away from the B participant will be yours. This B participant is randomly chosen.

Stranger treatment. In this treatment, each messenger (B type) is randomly and anonymously matched with a dictator (A type). The messenger's answer is implemented for the matched dictator if he or she does not choose information him/herself. Subjects are informed that if they are a B type, the following applies:

If you answer yes, this will ensure that a randomly chosen A person gets information. This randomly chosen A person will then see the table that applies for him/her on his/her screen. If the A person has asked for information him-/herself, your answer will not have any influence.

The dictator may take up to $50 \mathrm{NOK}$ from a random messenger's endowment, who is not the same subject who could impose information on the dictator. Participants are informed:

If you are type A, you will have the possibility to take up to 50 NOK from a participant of type B. If you use this possibility, the amount you take away from the B person will be yours. This B person is randomly chosen, and is not the same person who could ensure that you got to know which table applied for you. 
If the dictator does not press the button to ask for information herself, a screen appears indicating whether the B person matched with her has chosen to convey the information to her, and if so, displaying the correct table.

Partner treatment. This treatment is similar to the Stranger treatment, except that the dictator may take up to $50 \mathrm{NOK}$ from the same messenger's endowment who could impose information on her. Participants are informed:

If you are type A, you will have the possibility to take up to $50 \mathrm{NOK}$ from a participant of type B. If you use this possibility, the amount you take away from the B person will be yours. This B person is the same person who could ensure that you got to know which table was relevant for you.

In all treatments, the experiment was followed by a brief computer-based survey including socio-demographic questions, a few questions about the experiment, and respondents' agreement to the statements "Global warming is a serious societal problem" and "Donating to climate mitigation projects will help alleviate global warming".

All treatments took place at the University of Oslo's Oeconlab during February, March and April 2015, using the experimental software $z$-Tree (Fischbacher, 2007). ${ }^{8}$ Participants were recruited via e-mail and in beginners' lectures in various subjects, excluding economics and psychology. Instructions were distributed to all participants and read out aloud. Before the experiment started, each subject had to solve correctly a quiz testing their understanding of the experiment. The experiment was double anonymous, following Grossman and van der Weele's (2017) z-Tree implementation of Dana et al.'s (2007) design closely. ${ }^{9}$ Participants were informed that receipts for all payments to the charity would be copied and posted on one of the experimenters' web page (which we also did).

\section{Results}

\subsection{Baseline and Hidden Payoff}

We have 45 observations in the Baseline and 59 in the Hidden payoff treatment, of which 55 were in a conflict state. ${ }^{10}$ In Dana, Weber, and Kuang (2007), 26\% choose the selfish option in their baseline treatment, and 63\% in Hidden Payoff, counting only subjects in the conflict state. To detect a difference in proportions compared to this, 22 subjects per group would have been necessary to achieve a power of 0.8. Our sample sizes in Baseline and Hidden Payoff give

\footnotetext{
${ }^{8}$ Data from the experiment were imported using the user-written Stata command ztree2stata by Kan Takeuchi.

${ }^{9}$ In the experimental software, subject identity was recorded only as ID numbers, created by an algorithm with a random component. Subjects' ID numbers were provided to them privately on their screens. They noted their ID number, name and bank account number on the payment form, and put the form themselves into a visibly locked mailbox to be opened by the secretary of another research institution who handled the payments.

${ }^{10}$ See Appendix Table A.1 for a full overview of session compositions.
} 
a power of 0.9889 for this difference in proportions. Table 3 shows the main outcomes from the basic treatments of the experiment. First, we observe that only a small number of subjects choose to remain ignorant in the Hidden payoff treatment. In total, only $22 \%$ (13 out of 59) do not choose information in Hidden Payoff. ${ }^{11}$

If our subjects used the option to remain ignorant as an excuse to act selfishly, we should observe that more subjects choose $\mathrm{X}$ in our Hidden Payoff-treatment than in the Baseline. However, the difference we observe is small and statistically insignificant $(p=.4) .{ }^{12}$ In the Baseline treatment, where each dictator's interest conflicted with the receiver's, $18 \%$ chose the selfish and inefficient option X (8 out of 45), compared to the Hidden Payoff treatment, were 22\% (12 out of 55 subjects in conflicting states of interest) chose $X .^{13}$

Nonetheless, dictators' choice of information is systematic: $58 \%$ of ignorant dictators chose the selfish action X (7 out of 12), compared to only $11 \%$ of informed dictators ( 5 out of 43 ) in the case of conflicting states. Despite the small number of ignorant subjects, this difference is statistically significant $(p=.02)$. That is, although we cannot claim that the option to remain ignorant has a significant impact on the choice between $\mathrm{X}$ and $\mathrm{Y}$, there is an association between choosing ignorance and choosing the selfish alternative $\mathrm{X}$.

It is also somewhat surprising that almost $42 \%$ of the uninformed subjects choose the unselfish action Y, knowing that it would hurt them but not knowing whether it would benefit the charity. It could be that some of these were confused and believed that there always was a trade off between themselves and the charity.

We cannot claim that our Baseline subjects were more generous towards the charity than the subjects of Dana, Weber, and Kuang (2007) were towards their other subject recipients: the $95 \%$ exact binomial confidence interval for the proportion choosing $\mathrm{X}$ in Baseline ranges from .08 to .32 and includes the proportion choosing X in Dana, Weber, and Kuang (2007)'s baseline. In our Hidden Payoff, however, a considerably lower share of subjects chose to stay ignorant as compared to the corresponding treatment in Dana, Weber, and Kuang (2007). The exact binomial confidence interval for the proportion choosing information ranges from .65 to .88. Its lower bound is well above the proportion choosing information in Dana, Weber, and Kuang (2007)'s hidden payoff treatment (.50). Moreover, the proportion of $63 \%$ choosing X in their Hidden Payoff treatment is well above the upper bound of the confidence interval for the proportion choosing $\mathrm{X}$ in our Hidden Payoff-treatment, which ranges from .16 to .40.

So far we have only considered the effect of the experimental treatment, not taking into account that subjects' opinions on global warming issues may differ. We find no significant effects. Among the 104 subjects in the Baseline and Hidden Payoff treatments, only one does not agree with the statement that global warming is a serious societal problem. 23 out of 104 do not agree that donating to Myclimate will help the climate. While those with a moderate to

\footnotetext{
${ }^{11}$ Results adjusted for multiple hypotheses testing following List, Shaikh, and Xu (2016) can be found in Appendix Table A.4. Average earnings by treatment are listed in Appendix Table A.2.

${ }^{12}$ Unless otherwise noted, all p-values from binary tests are based on Fischer's exact test.

${ }^{13}$ Counting informed and uninformed dictators alike.
} 
Table 3: Behavior in Baseline and Hidden Payoff treatments

\begin{tabular}{|c|c|c|c|c|}
\hline & \multicolumn{2}{|c|}{ Baseline } & \multicolumn{2}{|c|}{ Hidden Payoff } \\
\hline & Subjects & Share & Subjects & Share \\
\hline Subjects choosing $X$ & 8 & $\begin{array}{c}.18 \\
{[.08 ; .32]}\end{array}$ & 12 & $\begin{array}{c}.22 \\
{[.12 ; .35]}\end{array}$ \\
\hline Subjects choosing information & & & 46 & $\begin{array}{c}.78 \\
{[.65 ; .88]}\end{array}$ \\
\hline Uninformed choosing $\mathrm{X}$ & & & 5 & $\begin{array}{c}.583 \\
{[.28 ; .85]}\end{array}$ \\
\hline Informed choosing $X$ & & & 7 & $\begin{array}{c}.12 \\
{[.04 ; .25]}\end{array}$ \\
\hline Total subjects & 45 & & 59 & \\
\hline
\end{tabular}

Notes: The table shows behavior in the Baseline and Hidden payoff treatments. In the latter treatment, only the 55 subjects in the conflict state are included in the analysis of the dictator. "Share" is the share of subjects choosing the selfish outcome $(X)$, and exact confidence intervals for proportions are shown in square brackets.

strong belief in the effectiveness of donating for climate action ("agree" or "strongly agree") are less likely (but insignificantly) to choose X (selfish) in the conflict state, there seems to be no connection to choosing information. Finally, men seem to be somewhat more inclined to choose the selfish option - see Appendix Table A.3 for details. ${ }^{14}$

\subsection{Messenger treatments}

Table 4 lists the number of subjects in the messenger treatments by treatment, subject type and state.

\subsubsection{Information choices and selfish behavior by dictators}

A players' choice of information acquisition and choice between actions $\mathrm{X}$ and $\mathrm{Y}$, as well as B types' choices to inform the As, can be found in Table 5 and Figure 1. We see from Figure 1a that in the Hidden Payoff treatment, where no messenger was present, the vast majority of

\footnotetext{
${ }^{14}$ Compared to the results by Dana, Weber, and Kuang (2007) and replications, the proportion of subjects that choose $\mathrm{Y}$ without information is rather high. Considering that without information, there is little reason to believe that $\mathrm{Y}$ is more likely to give a higher payoff to Myclimate, while one knows for sure that it gives a lower payoff to oneself, this observation is rather surprising. Recall, however, that the prevalence of ignorance is low, meaning that although the share of ignorant subjects choosing $\mathrm{Y}$ is high, it corresponds to a low number of subjects, possibly including some confused ones. Tjøtta (2018) finds that about one third of his subjects choose the lower payment in an experiment without any other recipient, and a minority thinks that choosing less is socially more appropriate. For some subjects, such views may matter more than the recipient's payoff.
} 
Table 4: Number of subjects in social interaction treatments by treatment, type and state

\begin{tabular}{lcccccc}
\hline Treatment & \multicolumn{3}{c}{ Dictators (A) } & & Messengers (B) & Total subjects \\
\cline { 2 - 4 } & Total & Conflict state & Aligned state & & \\
\hline Hypothetical messenger & 20 & 19 & 1 & & 20 & 40 \\
Stranger & 19 & 17 & 2 & & 19 & 38 \\
Partner & 30 & 27 & 3 & & 30 & 60 \\
\hline
\end{tabular}

Notes: Number of subjects in each treatment. The next three columns list the total number of subjects in the dictator role (type A), dictator subjects in the conflicting interest state and dictator subjects in the aligned interest state. The last column lists the number of subjects in the messenger role (Type B). The last column lists the total number of subjects in each treatment.

Figure 1: Dictator (A type) behavior in the social interaction treatments

(a) A types choosing information in the social interaction treatments

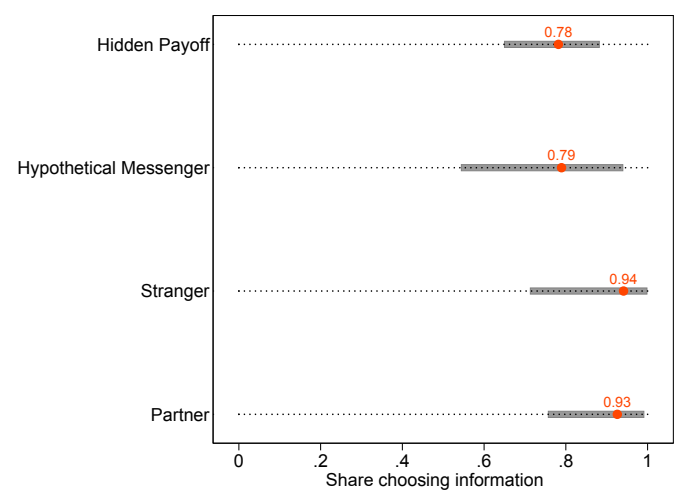

(b) A types choosing $\mathrm{X}$ in the social interaction treatments

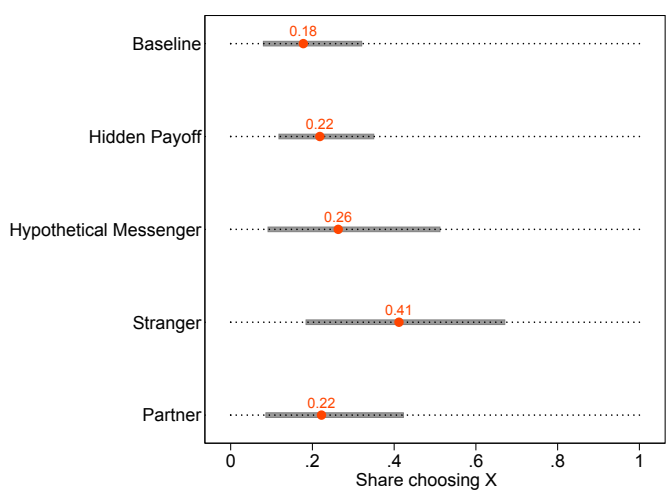

Notes: The red dots show the point estimates of the share of A types choosing to acquire information and choosing $X$ by treatment, with the grey lines indicating exact confidence intervals.

dictators (78\%) chose information themselves. In Hypothetical Messenger this share was 75\%, which is insignificantly different from the share showing information in Hidden Payoff ( $p=$ .5). Interestingly, however, in those conditions where information could be imposed, i.e. the pooled Stranger and Partner treatments, almost all dictators (a total of 94\%) chose information themselves. $^{15}$ Thus, while some dictators may dislike being informed, they seem to dislike even more to be imposed information upon by another subject. The difference between the pooled treatments where information could not be imposed (Hidden Payoff and Hypothetical Messenger) and the pooled treatments where the messenger could impose information on the dictator (Stranger and Partner) is significant at the 5\% level $(p=.01)$.

In previous studies, more ignorance has usually been associated with less generosity towards the recipient. It is thus interesting to note that while more dictators choose to press the reveal button themselves in Stranger and Partner, this does not increase generosity. From Figure 1b, we see that in the Stranger treatment, $41 \%$ choose X (selfish), and in the Partner treatment,

\footnotetext{
${ }^{15} 5 \%$ (1 out of 19) in Stranger and 7\% (2 out of 30) in Partner do not choose information.
} 
Table 5: Behavior in social interaction treatments

\begin{tabular}{|c|c|c|c|c|c|c|}
\hline & \multicolumn{2}{|c|}{ Hypothetical Messenger } & \multicolumn{2}{|c|}{ Stranger } & \multicolumn{2}{|c|}{ Partner } \\
\hline & Subjects & Share & Subjects & Share & Subjects & Share \\
\hline Choosing info & 15 & $\begin{array}{c}.79 \\
{[.54, .94]}\end{array}$ & 16 & $\begin{array}{c}.94 \\
{[.71, .99]}\end{array}$ & 25 & $\begin{array}{c}.93 \\
{[.76, .99]}\end{array}$ \\
\hline Choosing X & 5 & $\begin{array}{c}.26 \\
{[.09, .51]}\end{array}$ & 7 & $\begin{array}{c}.41 \\
{[.18, .67]}\end{array}$ & 6 & $\begin{array}{c}.22 \\
{[.09, .42]}\end{array}$ \\
\hline Total A subjects & 19 & & 17 & & 27 & \\
\hline Giving info & 18 & $\begin{array}{c}.90 \\
{[.68, .99]}\end{array}$ & 16 & $\begin{array}{c}.84 \\
{[.60, .97]}\end{array}$ & 22 & $\begin{array}{c}.73 \\
{[.54, .88]}\end{array}$ \\
\hline Total B subjects & 20 & & 19 & & 30 & \\
\hline Max sanctions & 4 & $\begin{array}{c}.21 \\
{[.06, .46]}\end{array}$ & 11 & $\begin{array}{c}.65 \\
{[.38, .86]}\end{array}$ & 10 & $\begin{array}{c}.37 \\
{[.19, .58]}\end{array}$ \\
\hline
\end{tabular}

Notes: The table shows behavior in the three social interaction treatments. Only the 55 dictators in the conflict state are included in the analysis. "Share choosing info" is the share of A subjects choosing information themselves, "Giving info" is the share of B subjects willing to provide information. "Max sanctions" is the share of A types taking the maximum possible amount from a $B$ type's endowment. Exact confidence intervals for proportions are shown in square brackets. 
$22 \%$ chose X, compared to $22 \%$ in the Hidden Payoff and $26 \%$ in the Hypothetical Messenger treatments. The difference between the pooled sample where information could only be chosen by the dictator (Hidden Payoff and Hypothetical Messenger) and the pooled sample where the messenger could impose information (Stranger and Partner) is not significant $(p=.28) .{ }^{16}$

Messengers' behavior seems to be little influenced by the possibility of being sanctioned (or by whether their answer is actually implemented), as seen from Table 5. In Hypothetical Messenger, $90 \%$ (18 out of 20) of messengers answer yes to giving information to a dictator that has not chosen information herself. This proportion decreases to 84\% (16 out of 19) in Stranger and to $73 \%$ (22 out of 30) in Partner. If messengers were more reluctant to answer yes when the possible implementation of this answer puts them into a loyalty conflict between being kind to the dictator and being kind to the receiver, we would expect a significant difference in the share giving information between Hypothetical Messenger and Stranger. But for the small difference we find, the p-value is .47. Only in Partner the dictator can sanction the messenger for the actual answer he gave by taking from his endowment. If messengers were discouraged by expected sanctions from giving information, we would expect the difference between Stranger and Partner to be significant, which it is not $(p=.3) .{ }^{17}$

Hence, we find no evidence that potential sanctions discourage the provision of information to another subject. Recall, however, that even in the Hidden Payoff treatment, there is very little ignorance. This may indicate that in this particular context, information is not that unwelcome, and suspecting this, messengers may not fear sanctions.

\subsubsection{No strong evidence for dictators sanctioning messengers}

A dictator was only informed about the messenger's "yes" or "no" answer if she had not asked for information herself. In those cases where dictators revealed the information themselves, which turned out to be most, the amount taken from the messenger can thus not, even in the Partner treatment, be interpreted as a sanction for the messenger's choice.

No dictator in Partner ended up being imposed information upon by a messenger. Thus we have no data to test how dictators react to receiving unwanted information. We observe that dictators took much more from messengers in general when messengers had the power to force the true payoff information upon dictators, compared to when the messenger's answer was purely hypothetical. In Hypothetical Messenger, dictators took on average NOK 16 from messengers, and $21 \%$ took everything they could. In Stranger, they took on average NOK 32, while $65 \%$ took the maximum. In Partner, dictators took on average NOK 22, 37\% took the maximum. The difference in average taking between Hypothetical Messenger and Stranger is statistically significant $(p=.03)$, the difference in the proportion of dictators taking the maximum is signif-

\footnotetext{
${ }^{16}$ Reported values include dictators in the conflict state only. The only significant difference in selfish behavior between single treatments is the one between Stranger and Partner (p: .07). We do not have a fully convincing explanation for this. It could be a false positive since procedures correcting for multiple testing yield no significant test results (see Appendix Table A.4.

${ }^{17}$ Note, however, that the Stranger-treatment has rather few observations.
} 
icant too (2-sided $p=.01) .{ }^{18}$ There is no statistically significant difference between Stranger and Partner in average taking (p:.3), nor in taking the maximum (2-sided $p=.21) .{ }^{19}$ When we pool the two treatments where information could be imposed (Stranger and Partner) to Hypothetical Messenger, we find a statistically significant difference in average taking $(p=.08)$ and taking the maximum (2-sided $p=.03$ ). More formal testing approaches accounting for multiple hypothesis tests are listed in Appendix Table A.4. No adjusted p-values for differences between treatments is then significant.

We also run a set of parametric regressions summarized in Appendix Table A.5. Generally, we find no statistically significant relationships. Dictators who choose information choose $\mathrm{X}$ less often. Males seem to choose X more often overall than females, but this difference largely disappears when attitudes to quotas are controlled for. More optimism towards quotas as a means to mitigate global warming and a stronger agreement with man-made global warming as a serious environmental problem is positively associated with generosity. Strong agreement with acquiring information being the morally right choice is positively associated with acquiring information.

\section{Conclusion}

In an experiment along the lines of Dana, Weber, and Kuang (2007), but with a climate charity as the recipient, we find no evidence of strategic ignorance. Although some subjects do not reveal the information about the payoff to Myclimate, this does not significantly reduce overall generosity. Our results are thus at odds with previous studies on willful ignorance.

Our initial intention was to explore, using additional treatments involving a third party, whether messengers conveying unwanted environmental information are faced with sanctions from those having unwanted information imposed on them. Further, our study was designed to explore whether anticipated sanctions prevent messengers from conveying the information in the first place. However, given that the information did not appear to be unwanted in our case, the experiment sheds less light on these questions than we had hoped for. Since strategic ignorance has repeatedly been observed in the literature, running messenger treatments in some context of more strongly unwelcome information is an interesting topic for future research.

Strategic ignorance means not only that individuals avoid information, but also that the option to avoid information reduces contributions. Thus, from an environmental policy perspective, it is important to understand why strategic ignorance sometimes appears and at other times does not. Providing more information to the public about environmental problems may even be counter-productive if people do not react by behaving more environment-friendly, but rather start avoiding situations in which they are likely to become informed. So why does in-

\footnotetext{
${ }^{18}$ Differences in taking from the messenger are tested using Pearson's $\chi^{2}$ tests.

${ }^{19}$ The difference in average taking between Hypothetical Messenger and Partner is not significant (p:.25), nor is the one in taking the maximum (.15).
} 
formation on the consequences of one's actions sometimes appear to be unwelcome, while in another context, with a similar material incentive structure, it is not?

It is thus of substantial interest to understand why we did not observe strategic ignorance in our experiment. Based on the current experiment, however, we cannot be certain about this. One potential explanation is that in contrast to most of the previous literature, the recipient in our experiment was a charity, not another experimental subject. However, in her experiment with a charity recipient, Exley (2016) observed a substantial level of strategic ignorance. Furthermore, a follow-up study by Pauls (2018), replicating our Baseline and Hidden Payoff treatments with student recipients, finds no evidence of strategic ignorance either.

The latter might suggest a subject pool effect: perhaps Norwegians have different norms concerning responsibility avoidance than subjects used in much of the previous literature. However, the results of Jacobsen, Eika, Helland, Lind, and Nyborg (2011) may speak against this hypothesis: in a dictator game with a charity recipient, they found that a substantial share of Norwegian subjects were willing to pay to escape the dictator situation.

It could be that an environmental charity changes behavior, particularly as the post-experimental survey indicates that almost all our subjects seem to agree that environmental concerns are important. Jacobsen, Eika, Helland, Lind, and Nyborg (2011) study contributions to the human rights charity Amnesty International.

Compared to Dana, Weber, and Kuang (2007), our dictators in treatments with hidden information were faced with ambiguity rather than uncertainty concerning the charity's payoffs, which may have affected their behavior (Haisley and Weber, 2010). Moreover, the true probability of the conflict state, which was not known to dictators, was as high as 90 percent; we doubt that subjects suspected this, but if they did, this may have affected their behavior (Feiler, 2014). Further, there is conflicting previous evidence on the importance of whether the choice to retrieve information is an active or passive one (Larson and Capra, 2009; Grossman, 2014)); in our case, subjects did not have to actively say no to information, but they had to push a "proceed" button to escape the information choice.

Without further studies, we are unable to identify whether any the above-mentioned explanations, or something completely different, caused our surprising results. Nevertheless, our results seem to indicate that strategic ignorance could be a quite fragile and/or context-dependent phenomenon, more so than one might expect based on the previous literature. If so, behavioral responses to information campaigns, and possibly other environmental policies, may depend crucially on the context in which information is being provided.

In a theoretical study, Nyborg (2011) finds that for strategic ignorance to arise (in the absence of outright self-deception), it is not sufficient that the information can potentially increase the perceived obligation to contribute; it is also necessary that in the situation without information, the perceived obligation to contribute is absent. The latter requirement could possibly lead to context dependency, since contribution and fairness norms often seem quite situationspecific. For example, by mentioning the climate charity early in our instructions, we may have 
created a context in which subjects felt morally responsible from the very outset. It is our hope, however, that future research can shed more light on these questions.

\section{References}

Bonferroni, C. E. (1936): “Teoria statistica delle classi e calcolo delle probabilità,” Pubblicazioni del R Istituto Superiore di Scienze Economiche e Commerciali di Firenze.

Brekke, K. A., G. KipperberG, And K. Nyborg (2010): "Social Interaction in Responsibility Ascription: The Case of Household Recycling," Land Economics, 86(4), 766-784.

Broberg, T., T. Ellingsen, And M. Johannesson (2007): "Is generosity involuntary?," Economics Letters, 94(1), 32-37.

CAmerer, C. (2003): "Behavioral Game Theory. Experiments in Strategic Interaction," Chapter 2, Princeton University Press.

Cameron, A. C., J. B. Gelbach, And D. L. Miller (2008): "Bootstrap-Based Improvements for Inference with Clustered Errors," Review of Economics and Statistics, 90(3), 414427.

Cappelen, A. W., T. Halvorsen, E. Ø. Sørensen, and B. Tungodden (2017): "Facesaving or fair-minded: What motivates moral behavior?," Journal of the European Economic Association, 15(3), 540-557.

Cappelen, A. W., U. H. Nielsen, E. Ø. Sørensen, B. Tungodden, and J.-R. Tyran (2013): “Give and take in dictator games," Economics Letters, 118(2), 280 - 283.

Cherry, T. L., AND J. Shogren (2008): "Self-interest, sympathy and the origin of endowments," Economics Letters, 101, 69-72.

Cox, J. C., J. A. List, M. Price, V. SAdiraj, And A. S AmeK (2016): “Moral Costs and Rational Choice: Theory and Experimental Evidence," NBER Working Paper 22234, National Bureau of Economic Research, Inc.

D’Adda, G., Y. GaO, R. Golman, and M. TAvoni (2018): "It's So Hot in Here: Information Avoidance, Moral Wiggle Room, and High Air Conditioning Usage," Working Papers 2018.07, Fondazione Eni Enrico Mattei.

Dana, J., D. M. CAin, And R. M. Dawes (2006): "What you don't know won't hurt me: Costly (but quiet) exit in dictator games," Organizational Behavior and Human Decision Processes, 100(2), 193-201. 
DANA, J., R. WEBER, AND J. KUANG (2007): "Exploiting moral wiggle room: experiments demonstrating an illusory preference for fairness," Economic Theory, 33(1), 67-80.

DellaVigna, S., J. A. List, And U. Malmendier (2012): “Testing for Altruism and Social Pressure in Charitable Giving," The Quarterly Journal of Economics, 127(1), 1-56.

Eckel, C. C., And P. J. Grossman (1996): "Altruism in Anonymous Dictator Games," Games and Economic Behavior, 16(2), 181-191.

ENGEL, C. (2011): “Dictator games: a meta study,” Experimental Economics, 14, 583âĂŞ610.

EXLEy, C. L. (2016): "Excusing Selfishness in Charitable Giving: The Role of Risk," Review of Economic Studies, 83(2), 587-628.

FEILER, L. (2014): "Testing models of information avoidance with binary choice dictator games," Journal of Economic Psychology, 45(C), 253-267.

FELGENDREHER, S. (2018): "Do consumers choose to stay ignorant? The role of information in the purchase of ethically certified products," Working Paper in Economics No. 717, University of Gothenburg.

FISCHBACHER, U. (2007): "z-Tree: Zurich toolbox for ready-made economic experiments," Experimental Economics, 10(2), 171-178.

FonG, C. M. (2007): "Evidence from an Experiment on Charity to Welfare Recipients: Reciprocity, Altruism and the Empathic Responsiveness Hypothesis," The Economic Journal, 117(522), 1008-1024.

Grossman, Z. (2014): “Strategic Ignorance and the Robustness of Social Preferences," Management Science, 60(11), 2659-2665.

Grossman, Z., AND J. VAN DER WEELE (2017): "Self-Image and Willful Ignorance in Social Decisions," Journal of the European Economic Association, 15(1), 173-217.

Haisley, E. C., AND R. A. Weber (2010): "Self-serving interpretations of ambiguity in other-regarding behavior," Games and Economic Behavior, 68(2), 614-625.

Hertwig, R., And C. Engel (2016): "Homo Ignorans: Deliberately Choosing Not to Know," Perspectives on Psychological Science, 11(3), 359-372.

Holm, S. (1979): “A Simple Sequentially Rejective Multiple Test Procedure,” Scandinavian Journal of Statistics, 6(2), 65-70.

Jacobsen, K. J., K. H. EikA, L. Helland, J. T. Lind, And K. Nyborg (2011): “Are nurses more altruistic than real estate brokers?," Journal of Economic Psychology, 32(5), 818-831. 
LARSON, T., AND C. M. CAPRA (2009): "Exploiting moral wiggle room: Illusory preference for fairness? A comment," Judgment and Decision Making, 4(6), 467-474.

Lazear, E. P., U. Malmendier, And R. A. Weber (2012): "Sorting in Experiments with Application to Social Preferences," American Economic Journal: Applied Economics, 4(1), 136-163.

List, J. A. (2007): “On the Interpretation of Giving in Dictator Games," Journal of Political Economy, 115, 482-493.

List, J. A., A. M. ShaikH, And Y. XU (2016): "Multiple Hypothesis Testing in Experimental Economics," Working Paper 21875, National Bureau of Economic Research.

Matthey, A., And T. Regner (2011): "Do I Really Want to Know? A Cognitive DissonanceBased Explanation of Other-Regarding Behavior," Games, 2(1), 114-135.

NybORG, K. (2011): “I don't want to hear about it: Rational ignorance among duty-oriented consumers," Journal of Economic Behavior \& Organization, 79(3), 263-274.

PAuls, A. (2018): “Strategic ignorance and context,” Mimeo, UiO.

Regner, T., And A. MAtThey (2015): "Do reciprocators exploit or resist moral wiggle room? An experimental analysis," Jena Economic Research Paper 2015-027, FriedrichSchiller-University Jena.

SPIEKERMANN, K., AND A. WEISS (2016): “Objective and subjective compliance: a normbased explanation of 'moral wiggle room'," Games and Economic Behavior, 96, 170-183.

Thunström, L., T. L. Cherry, D. M. McEvoy, And J. F. Shogren (2016): “Endogenous context in a dictator game," Journal of Behavioral and Experimental Economics, 65, 117120.

ТјøттА, S. (2018): "You'll never walk alone. An experimental study on receiving money," Mimeo, University of Bergen.

VAN DER WeELE, J. J. (2014): “Inconvenient Truths: Determinants of Strategic Ignorance in Moral Dilemmas," SSRN Scholarly Paper ID 2247288, Social Science Research Network, Rochester, NY.

VAn Der Weele, J. J., J. Kulis A, M. Kosfeld, And G. Friebel (2014): "Resisting Moral Wiggle Room: How Robust Is Reciprocal Behavior?," American Economic Journal: Microeconomics, 6(3), 256-264.

WeBB, M. D. (2014): "Reworking Wild Bootstrap Based Inference for Clustered Errors," Working Paper 1315, Queen's University, Department of Economics. 


\section{A Additional tables and figures}

Table A.1: Number of subjects by treatment, type, and state

\begin{tabular}{|c|c|c|c|c|c|}
\hline \multirow[t]{2}{*}{ Treatment } & \multicolumn{3}{|c|}{ Dictators } & \multirow[t]{2}{*}{ Messengers } & \multirow[t]{2}{*}{ Total } \\
\hline & Total & Conflict & Aligned & & \\
\hline \multicolumn{6}{|l|}{ Basic treatments } \\
\hline Baseline & 45 & 45 & 0 & & \\
\hline Hidden payoff & 59 & 55 & 4 & & \\
\hline \multicolumn{6}{|c|}{ Social interaction treatments } \\
\hline Hypothetical messenger & 20 & 19 & 1 & 20 & 40 \\
\hline Stranger & 19 & 17 & 2 & 19 & 38 \\
\hline Partner & 30 & 27 & 3 & 30 & 60 \\
\hline
\end{tabular}

Notes: Number of subjects in each treatment. The next three columns list the total number of subjects in the dictator role (type A), dictator subjects in the conflicting interest state and dictator subjects in the aligned interest state. The second last column lists the number of subjects in the messenger role (Type B). The last column lists the total number of subjects in each treatment. 
Table A.2: Mean earnings and payments to Myclimate

\begin{tabular}{lccc}
\hline & Dictators & Messengers & Myclimate \\
\hline $\begin{array}{l}\text { Individual decision part } \\
\text { Baseline }\end{array}$ & 103.56 & & \\
& $(7.73)$ & & 85.78 \\
& & & $(30.93)$ \\
Hidden Payoff & 105.42 & & 83.73 \\
& $(8.97)$ & & $(32.48)$ \\
Social interaction part & & & \\
Hypothetical messenger & 123.25 & 82.75 & 40 \\
& $(28.30)$ & $(20.87)$ & $(47.51)$ \\
Stranger & & & \\
& 141.05 & 68.42 & 35.26 \\
Partner & $(29.42)$ & $(24.78)$ & $(45.19)$ \\
& & & \\
& 127.33 & 78.67 & 42 \\
& $(28.37)$ & $(23.27)$ & $(48.11)$ \\
\hline
\end{tabular}

Notes: The table shows average payments to dictators (A players) and messengers (B players) as well as payments to Myclimate by treatment. Standard deviation in parentheses. Note that since messengers could not donate to Myclimate, its average earnings in the social interaction part are about half of those in the basic treatments. 
Table A.3: The self-serving choice $\mathrm{X}$ in the basic treatments

\begin{tabular}{lccc}
\hline & $(1)$ & $(2)$ & $(3)$ \\
\hline Hidden Payoff & 0.0404 & 0.0754 & 0.0782 \\
& $(1.130)$ & $(0.167)$ & $(0.067)$ \\
Male & & 0.127 & 0.102 \\
& & $(0.082)$ & $(0.052)$ \\
Agreement warming quotas high & & & -0.238 \\
& & & $(0.211)$ \\
Constant & & & \\
& 0.178 & 0.119 & 0.315 \\
& $(0.151)$ & $(0.097)$ & $(0.295)$ \\
\hline Observations & 100 & 99 & 99 \\
\hline
\end{tabular}

Notes: The Table shows regressions of a dummy for A subjects choosing $X$ in the basic treatments, their view about global warming as a serious problem of society, and the reduction of global warming by donating to measures for improvement of the climate.

Standard errors clustered at the session level, computed using the wild bootstrap (Cameron, Gelbach, and Miller, 2008), using weights for few clusters (Webb, 2014), are shown in parentheses. 


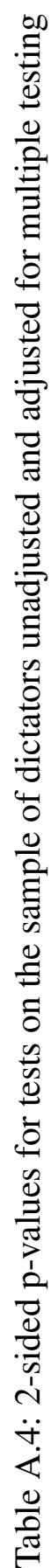

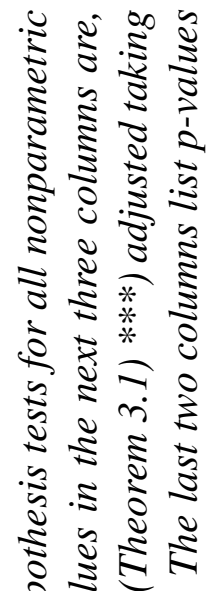

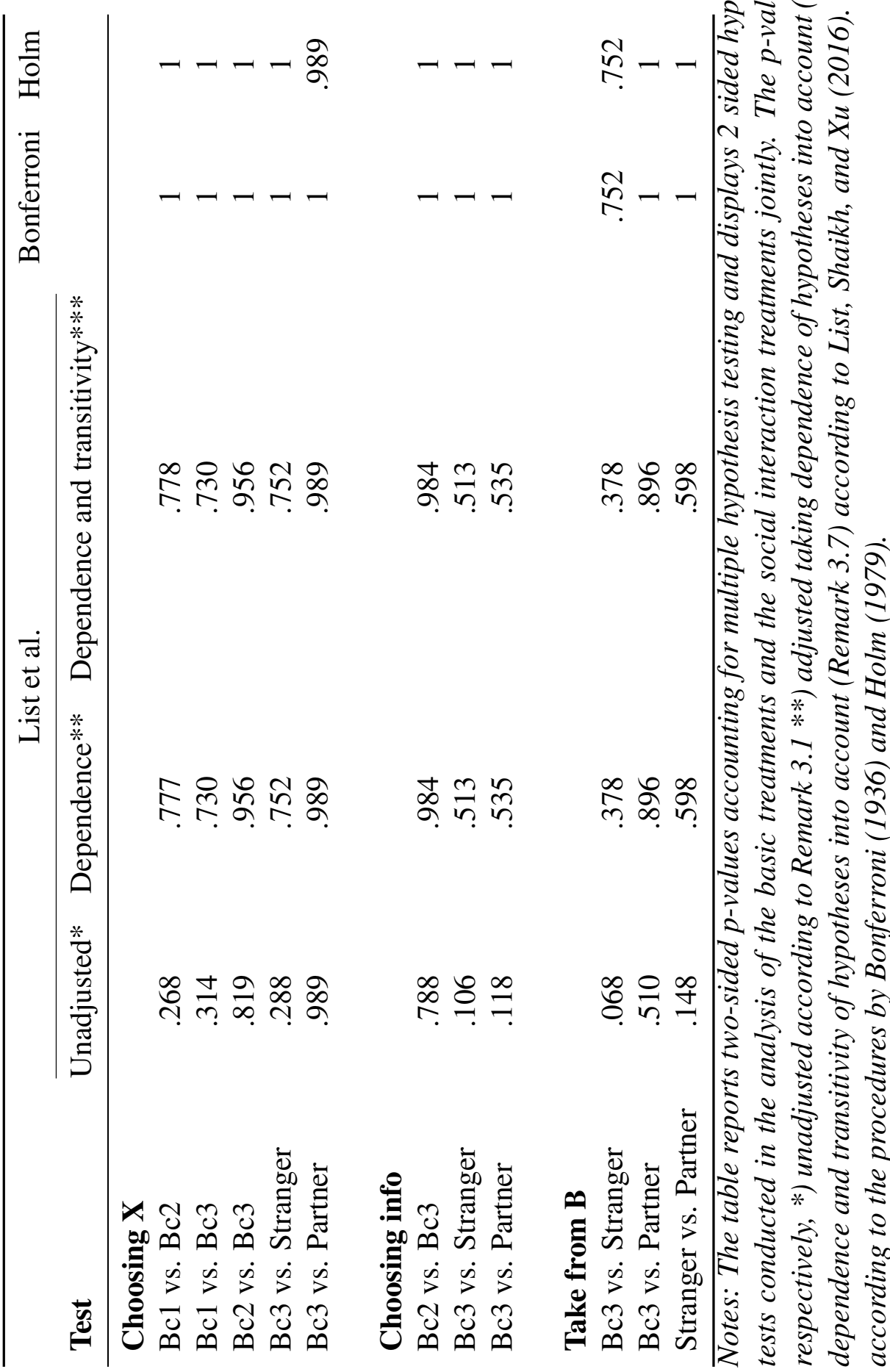


Table A.5: Choice of $\mathrm{X}$ - the self-serving choice

\begin{tabular}{|c|c|c|c|c|}
\hline & (1) & (2) & (3) & (4) \\
\hline Choose info & $\begin{array}{c}-0.422 \\
{[-1.280,0.436]}\end{array}$ & $\begin{array}{c}-0.413 \\
{[-1.299,0.473]}\end{array}$ & $\begin{array}{c}-0.436 \\
{[-1.274,0.403]}\end{array}$ & $\begin{array}{c}-0.373 \\
{[-0.957,0.211]}\end{array}$ \\
\hline Hypothetical Messenger & $\begin{array}{c}0.0482 \\
{[-0.130,0.226]}\end{array}$ & $\begin{array}{c}0.0150 \\
{[-0.108,0.138]}\end{array}$ & $\begin{array}{c}0.0406 \\
{[-0.256,0.337]}\end{array}$ & $\begin{array}{c}0.0399 \\
{[-0.279,0.359]}\end{array}$ \\
\hline Stranger & $\begin{array}{c}0.261 \\
{[-0.417,0.939]}\end{array}$ & $\begin{array}{c}0.176 \\
{[-0.229,0.580]}\end{array}$ & $\begin{array}{c}0.176 \\
{[-0.199,0.552]}\end{array}$ & $\begin{array}{c}0.184 \\
{[-0.069,0.437]}\end{array}$ \\
\hline Partner & $\begin{array}{c}0.0649 \\
{[-0.145,0.275]}\end{array}$ & $\begin{array}{c}0.00493 \\
{[-0.045,0.055]}\end{array}$ & $\begin{array}{c}-0.0109 \\
{[-0.281,0.260]}\end{array}$ & $\begin{array}{c}-0.0115 \\
{[-0.214,0.191]}\end{array}$ \\
\hline Male & & $\begin{array}{c}0.155 \\
{[-0.014,0.323]}\end{array}$ & $\begin{array}{c}0.0786 \\
{[-0.016,0.173]}\end{array}$ & $\begin{array}{c}0.0770 \\
{[-0.028,0.182]}\end{array}$ \\
\hline Agreement warming quotas high & & & $\begin{array}{c}-0.375 \\
{[-0.950,0.200]}\end{array}$ & $\begin{array}{c}-0.341 \\
{[-0.962,0.280]}\end{array}$ \\
\hline Show table morally right & & & & $\begin{array}{c}-0.132 \\
{[-0.331,0.067]}\end{array}$ \\
\hline Constant & $\begin{array}{c}0.548 \\
{[-0.450,1.547]}\end{array}$ & $\begin{array}{c}0.509 \\
{[-0.359,1.377]}\end{array}$ & $\begin{array}{c}0.849 \\
{[-0.251,1.949]}\end{array}$ & $\begin{array}{c}0.849 \\
{[-0.146,1.844]}\end{array}$ \\
\hline Observations & 118 & 115 & 115 & 115 \\
\hline$R^{2}$ & 0.145 & 0.176 & 0.294 & 0.313 \\
\hline
\end{tabular}

Notes: The Table shows shows results from regressions of a dummy for choosing $X$ (the selfserving choice) on whether the subject chooses to see the true payoff table, treatment dummies, a dummy for male subjects, and agreement with both global warming to be a serious societal problem and quotas and with donating to measures for improvement of the climate to reduce global warming.

95\% confidence intervals are shown in brackets, based on standard errors clustered at the session level using the wild bootstrap (Cameron, Gelbach, and Miller, 2008) using weights for few clusters (Webb, 2014). 


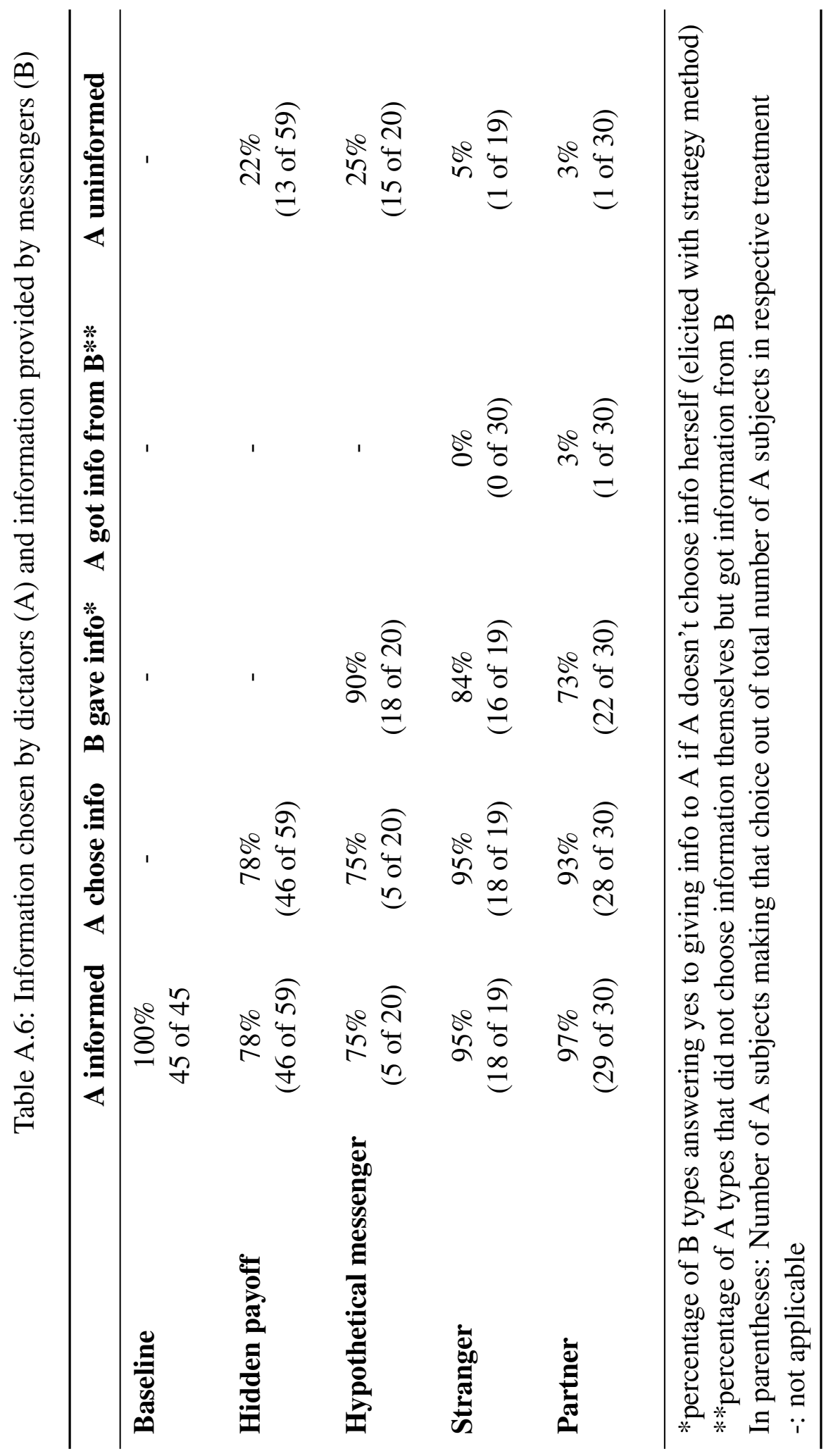


Table A.7: Dictators (A) taking from messengers (B), only dictators in misaligned state

\begin{tabular}{lc}
\hline $\begin{array}{l}\text { Hypothetical messenger } \\
\text { Mean taking }\end{array}$ & 15.79 \\
& $(20.36)$ \\
Taking maximum & $21 \%$ \\
& $(4$ of 19$)$ \\
& \\
Stranger & 32.35 \\
Mean taking & $(24.63)$ \\
& $65 \%$ \\
Taking maximum & $(11$ of 17$)$ \\
& \\
Partner & \\
Mean taking & 21.85 \\
& $(23.17)$ \\
Taking maximum & $37 \%$ \\
& $(10$ of 27$)$ \\
\hline
\end{tabular}

Notes: Mean taking: arithmetic mean of amount taken. Standard deviation in parenthesis Taking maximum: proportion of A subjects who take the maximum amount. Number taking maximum out of total number of A subjects in respective treatment in parentheses. 